\title{
Mitral-aortic annular enlargement: modification of Manouguian's technique
}

\author{
Ampliação anular mitro-aórtica: modificação da técnica de Manouguian
}

Mario Gesteira COSTA, Frederico P. VASCONCELLOS E SILVA, Alexandre Mota de MENEZES, Ricardo de Carvalho LIMA, Mozart ESCOBAR, Antônio Carlos C. LEÃO, André Luis ANDRADE, Marcos Vinícius F. de LUCENA.

RBCCV 44205-610

\section{Abstract:}

We hereby present a technical modification for mitral-aortic annular enlargement. The mitral valve is replaced through the retro-septal approach, avoiding patches for left atrial roof closure. We report a mitral-aortic valve replacement in a patient whose original annuli would preclude adequate prostheses. The simultaneous annular enlargement may be necessary for avoiding patient-prosthesis mismatch and for reconstructing destroyed mitral and aortic annuli. The technique may minimize the risk of bleeding and of paravalvular leakage, using an approach well known to cardiac surgeons.

Descriptors: Cardiac surgical procedures, methods. Heart valves, surgery. Aortic valve. Mitral valve.

\section{INTRODUCTION}

Implantation of small aortic annulus prostheses can lead to a prosthesis-patient mismatch and the subsequent consequences $[1,2]$. Small mitral prostheses are also obstructive [3], and are rarely indicated. Manouguian's technique allows the implantation of adequate prostheses by simultaneously increasing the aortic and mitral valves [4,5]. Here we report on a modification of this technique, we present a case report and discuss these modifications and the technique's indication.

\section{Resumo}

Apresentamos uma modificação técnica para ampliação anular mitro-aórtica. A prótese mitral é implantada pela via retrosseptal, evitando retalhos para fechar o teto atrial esquerdo. Relatamos um implante valvar mitro-aórtico em paciente cujos anéis originais impossibilitariam próteses adequadas. A ampliação pode ser necessária para evitar a inadequação prótese-paciente ou para reconstruir anéis mitral e aórtico destruídos. Esta técnica pode diminuir o risco de sangramento e de vazamento paravalvar, utilizando um acesso bem conhecido por cirurgiões cardíacos.

Descritores: Procedimentos cirúrgicos cardíacos, métodos. Valvas cardíacas, cirurgia. Valva aórtica. Valva mitral.

\section{TECHNIQUE}

The aortotomy was directed to the commissure between the left cuspids and not the coronary artery and the aortic valve was removed (Figure 1-A). The annulus was measured and, when an increase was required, the inter-valvular trigone was transected to $2 \mathrm{~mm}$ from the mitral annulus (Figure 1-B), checking again to see whether the diameter was adequate. If necessary the mitral valve was removed by retro-septal atriotomy. In cases where the mitral or aortic valve diameters

Cardiac Surgery Department of Unicárdio - Hospital Memorial São José. Avenida Agamenon Magalhães 2291, Recife - PE CEP 50100-010 Corresponding author:

Mario Gesteira Costa.

Rua Iramaia 1156, Recife - PE 50070-530.

Fone: (81) 3231-6013

Fax: (81) 3221-4148

Email: mariogesteiracosta@hotmail.com

Work presented at the $29^{\text {th }}$ National Congress of Cardiac Surgery in

Natal, Brazil on $06 / 04 / 02$ 
continued to be insufficient, we returned to the aortic root, visualizing the mitral annulus and placed repair sutures using 4-0 polypropylene thread at a distance of $2 \mathrm{~mm}$ from the junction with the inter-valvular trigone (Figure 1-C). We sectioned between the sutures (Figure 1-D), displacing the left atrial roof by approximately $10 \mathrm{~mm}$ at the trigone junction with the mitral annulus, as was described by MANOUGUIAN et al. [4,5], but we did not extend the opening. The annuli were increased simultaneously with a bovine pericardial patch in the shape of a Gothic arch. The base width determined the increase in the diameter of the mitral annulus. This base was calculated by multiplying the desired increase in millimeters by 3.1416 and increasing this by $4 \mathrm{~mm}$, which was the expected loss due to the lateral sutures. For example, to increase by $4 \mathrm{~mm}$, the base width would need to be 16.5

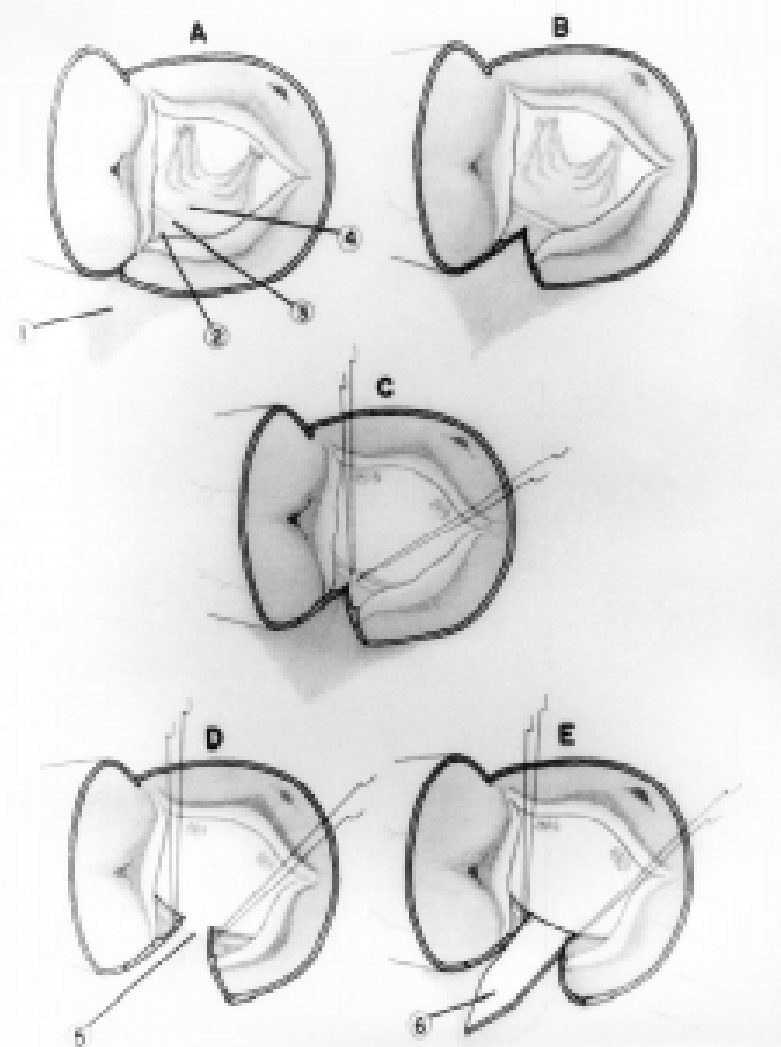

Fig. 1 - Surgical technique. 1) Left atrial roof. 2) Inter-valvular trigone. 3) Mitral annulus. 4) Anterior mitral leaflet. 5) Opening of the left atrial roof. 6) Bovine pericardial patch.

mm. U-shaped sutures using 4-0 polypropylene between each border of the mitral annulus and the base of the patch were made (Figure 1-E). The atrial roof closure was achieved, re-implanting it in the base of the patch using interrupted Ushaped sutures of 2-0 pledgeted braided polyester from the outside inwards. The lateral sutures incorporated the base of the patch and the transected annulus, insuring perfect co-adaptation (Figure 2-F).
The aortic annulus was widened using continuous sutures of 4-0 polypropylene starting from the base of the patch, suturing the border corresponding to the inter-valvular trigone with the patch and the sutures were interrupted about $5 \mathrm{~mm}$ above the level of the preexistent commissure (Figure 2$\mathrm{G})$. The width of the patch at the level of this commissure determines the increase in the diameter of the aortic annulus, as at this point the sutures fixing the aortic prosthesis will be placed. The width of the patch to obtain a specific increase can be calculated identically to the method previously mentioned for the mitral annulus. The aortic annulus at this position was measured checking to ensure an appropriate prosthetic size. The mitral prosthesis was implanted employing the normal method (Figure 2-H). The patch and the mitral annuls should be joined using U-shaped sutures at the two contact points of these structures. The left atrium was closed. The aortic prosthesis was implanted inserting the sutures of the aortic annulus as far as the patch at the commissural level mentioned above. Here the sutures were from the outside

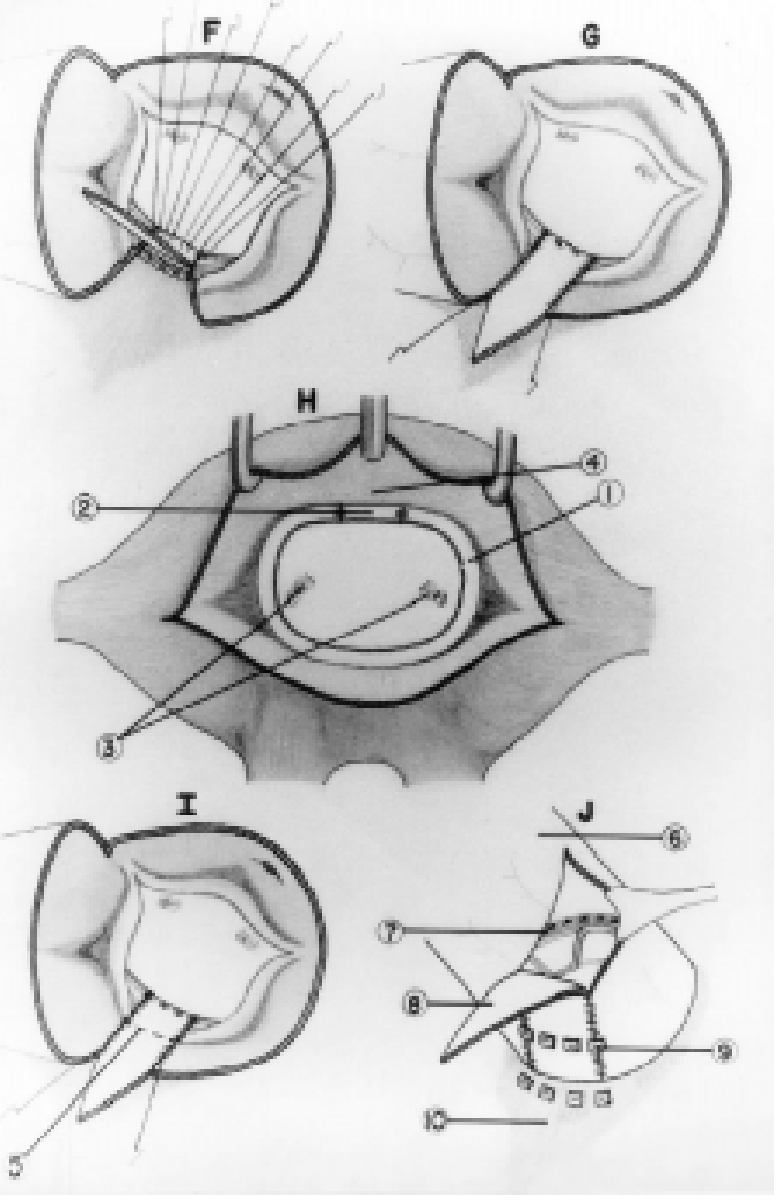

Fig. 2 - Surgical technique. 1) Mitral annulus. 2) Bovine pericardial patch base seen through the left atrial. 3) Papillary muscles. 4) Left atrial roof. 5) Fixation level of the aortic prosthesis on the bovine pericardial patch. 6) Aorta. 7) Aortic prosthesis. 8) Bovine pericardial patch. 9) Fixation sutures of the aortic prosthesis. 10) Left atrial roof. 
inwards in a U-shape reinforced by 'pledgets' (Figure 2-I). The lateral sutures should include the juxta-commissural annulus and the patch (Figure 2-J). The sutures are passed through the prosthesis and are tied. The aortotomy is closed remodeling the patch.

\section{CASE REPORT}

A 25-year-old female patient with functional class III was diagnosed as suffering from aortic stenosis and mitral insufficiency. A heart catheterism demonstrated a left aortic ventricular gradient of $104 \mathrm{mmHg}$, a small aortic annulus, moderate mitral insufficiency and good left ventricular function (Figure 3-A and 3-B). Mitral and aortic prostheses were indicated. During the surgery, an aortic annulus of 17mm diameter was evidenced, which reached $21 \mathrm{~mm}$ after incision of the inter-valvular trigone. A retro-septal left atriotomy was performed, and a mitral valve, which was inapt for reconstruction was encountered, whose annulus would only allow the implantation of a $23-\mathrm{mm}$ prosthesis The technique described above permitted the implantation of aortic and mitral disc prostheses with diameters of 23 and 27 $\mathrm{mm}$ respectively. The re-implantation of the left atrial roof and the other suture lines proved to be perfect without leakage.

A post-operative Doppler echocardiography demonstrated normally functioning prostheses, in the correct anatomical position with ejection fraction of $75 \%$, left ventricular atrial gradient of $2.4 \mathrm{mmHg}$ and left aortic ventricular gradient of $5.5 \mathrm{mmHg}$. The left ventricle outflow tract was seen to be unobstructed. A heart catheterism

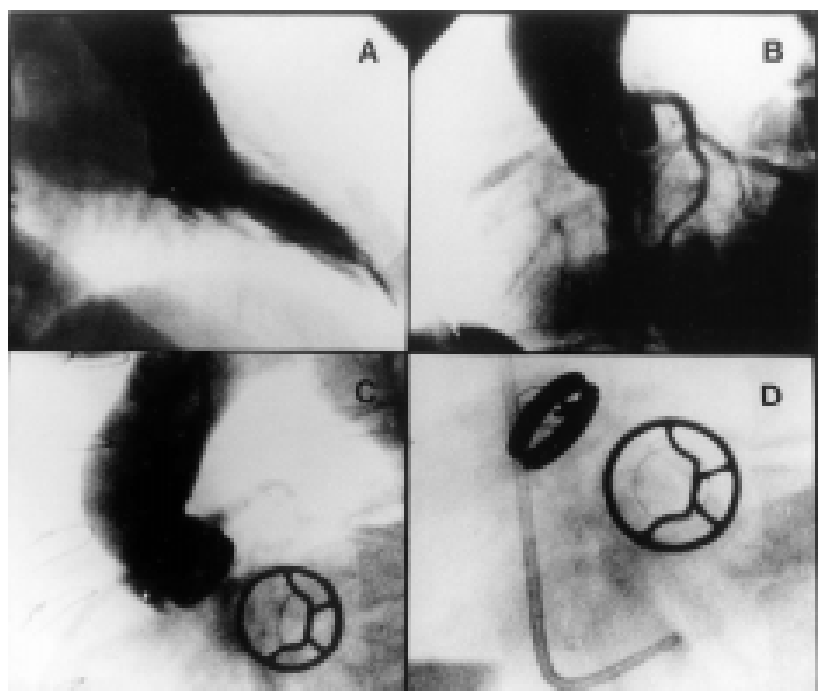

Fig. 3 - A) Pre-operative ventriculography demonstrating mitral insufficiency. B) Pre-operative aortogram demonstrating a small annulus. C) Post-operative aortogram demonstrating the competent aortic prosthesis and mitral prosthesis in diastole, in correct anatomical positions. performed on the $12^{\text {th }}$ operative day also evidenced normally functioning prostheses in the correct anatomical positions (Figure 3-C and 3-D) with a free left ventricular outflow tract, an aortic pressure of $100 \mathrm{mmHg}$ and a pulmonary capillary pressure of $12 \mathrm{mmHg}$. The patient was followed-up in the outpatient clinic as functional class I, and was referred to another physician on the $30^{\text {th }}$ post-operative day.

\section{COMMENTS}

Aortic prosthesis implantation in patients with small annuli remains problematic. Prostheses with external diameters of 19 to $21 \mathrm{~mm}$ cause obstructions of the left ventricular outflow tract, mainly during exercise [1]. A prosthesis-patient mismatch should be avoided, as it can cause a persistence or an increase of hypertrophy and left ventricular dysfunction, hemolysis, embolia and even reduced survival. Mitral prostheses with external diameters of 24 to $26 \mathrm{~mm}$ reach small gradients with flow rates of 5 liters per minute but reach from 9 to $17.6 \mathrm{mmHg}$ with flow rates of 9 liters per minute, offering an effective area of $1.6 \mathrm{~cm}^{2}$. Smaller mitral prostheses than these can limit the cardiac reserve [3].

Manouguian's technique opens the left atrial roof, widens this opening which is used for annulus enlargement and implants the mitral prosthesis. This roof is closed by reconstruction with a patch [4,5]. Mitral and aortic valves each obtain a 4-mm increase in diameter. In our modification, the small opening in the left atrial roof is not enlarged or utilized as access for mitral prosthesis implantation, utilizing instead a retro-septal approach. The enlargement of the mitral annulus and the closure of the atrial roof precede the enlargement of the aortic annulus and the implantation of the mitral prosthesis, allowing adequate access and perfect apposition of the sutures. Closure of the atrial roof becomes easier and without tension, without the necessity of patches, in a region whose access is difficult in the case of bleeding after aortic declamping. The technique permits the implantation of adequate prostheses, with mitral and aortic annuli enlargement of $4 \mathrm{~mm}$ and $6 \mathrm{~mm}$ respectively, thus obtaining satisfactory clinical and hemodynamic results.

The enlargement of annuli may be necessary in patients who require widening of the aortic annulus and mitral prosthesis implantation in cases where the mitral annulus does not allow the implantation of a prosthesis with a external diameter of 25-mm or greater. It can also be necessary in mitralaortic reoperations or surgeries for complicated endocarditis that require reconstruction of the mitral and aortic annuli $[6,7]$. The necessity of simultaneous amplification is rare, but the surgeon must be prepared, thus avoiding prostheses, which can potentially limit the cardiac reserve. This technique offers some simplification, providing an approach that cardiac surgeons know well, can result in a lower risk of bleeding and lower risk of paravalvular leakage. 


\section{BIBLIOGRAPHIC REFERENCES}

1. Becker RM, Strom J, Frishman W, Oka Y, Lin YT, Yellin EL et al. Hemodynamic performance of the Ionescu-Shiley valve prosthesis. J Thorac Cardiovasc Surg 1980; 80: 613-20.

2. Rahimtoola SH. The problem of valve prosthesis-patient mismatch. Circulation 1978; 58: 20-4.

3. Gabbay S, McQueen DM, Yellin EL, Becker RM, Frater RW. In vitro hydrodynamic comparison of mitral valve prostheses at high flow rates. J Thorac Cardiovasc Surg 1978; 76: 771-87.

4. Manouguian S, Abu-Aishah N, Neitzel J. Patch enlargement of the aortic and mitral valve rings with aortic and mitral double valve replacement: experimental study. J Thorac Cardiovasc Surg 1979; 78: 394-401.

5. Manouguian S, Kirchhoff PG. Patch enlargement of the aortic and the mitral valve rings with aortic-mitral double-valve replacement. Ann Thorac Surg 1980; 30: 396-9.

6. David TE, Feindel CM, Armstrong S, Sun Z. Reconstruction of the mitral annulus: a ten-year experience. J Thorac Cardiovasc Surg 1995; 110: 1323-32.

7. David TE, Kuo J, Armstrong S. Aortic and mitral valve replacement with reconstruction of the intervalvular fibrous body. J Thorac Cardiovasc Surg 1997; 114: 766-72. 